\title{
The Auto control System Based on InTouch Configuration software for High-gravity Oil Railway Tank Feeding
}

\author{
De-Kai XU,Li-Jie WANG,Wei-Chao SHI \\ Xi'an university of Technology, X'an, 710082, China
}

\begin{abstract}
This paper provides automatic design for high-gravity oil railway tank feeding system of some refinery uses distributive control system. The system adopts the automatic system of Modicon TSX Quantum or PLC as monitor and control level and uses a PC-based plat form as principal computer running on the Microsoft Windows2000. An automatic control system is developed in the environment of InTouch configuration software. This system implements automatic high-gravity oil tank feeding with pump controlling function. And it combines automatic oil feeding controlling, pump controlling and tank monitoring function to implement the automation of oil feeding with rations and automatic control.
\end{abstract}

\section{Introduction}

InTouch configuration software is produced by Wonderware Corporation. The software has standard windows operating system, Chinese operator interface, color graphics. The alarm information can be shown by using the different color, sound to present the equipment operating status and fault. In the articles [1-3], the Intouch software is composed with Matlab to cope with the vision and image, the method was very useful. Cosimulation and simulation integration for a full vehicle dynamic system [4,5], toward a model integration methodology for advanced application in power engineering [6] have been developed. The direct communication between Matlab and Intouch, design and application of Intouch in cold tandem mill control system were presented in the articles $[7,8]$. The model and algorithm of optimized organization scheme for through trains from loading points based on endpoint-for-weigh is presented in the article [9]. The organization of wagon flow in heavy haul loading area is studied in the article [10]. The collaborative optimization model of the loaded $\&$ empty car flow routing and the empty car distribution of multiple car types is shown in the article [11]. The optimization model of car flow organization in the loading area of heavy haul railway based on the combined trains is studied in the article [12]. The incremental PID barrier control system used in railway crossing, improved wavelet neural network based on hybrid genetic algorithm application on fault diagnosis of railway rolling bearing were shown in article [13]. The oil is filled into the oil tank of the train is a large work, so this work will be automatic control is a good program.

This article is based on the articles which were mentioned in the former. The loading system in the train oil loading station light oil automatic loading, and increase the oil pump control functions, automatic filling and oil pump automatically control and tank monitoring combined to achieve the quantitative filling of oil control and pump control automation of the whole process. In the safe production, energy efficient, reduce environmental pollution, improve the economic aspects will play a significant effect. The system renovation project includes the light oil loading platform part, part of the air station, light oil pumping station and tank farm part. For the light oil loading system renovation project automatic control system to better monitor and control, the Intouch software is used to comprehensive solve the automatic quantitative filling monitoring of tankers, oil filling process and equipment monitoring the operation of the oil pump monitoring, oil explorer automatically adjusts the hydraulic overload protection to prevent the filling of oil the oil overflow occurs Mao you accident, lost oil Explorer overpressure protection, gasoline, diesel fuel storage tanks to prevent the time compression process issues to clean up the air pressure is too low the pump stops and monitoring equipment operating status of the storage and transportation systems, to ensure that the entire system is smooth, safe and reliable operation, laying a solid foundation.

\footnotetext{
a Corresponding author: 452763124@qq.com
} 


\section{Design of System Structure}

\subsection{System introduce}

The system design uses a distributed control system. For adapt to the needs of the production process of the renovation project, production automation and management level, improve product yield and quality, reduce costs, and improve labor productivity, the Schneider's Modicon TSX Quantum automation series PLC is used as detection and the control stage in the system, which is divided into a main station and a plurality of RIO sub-station. The DELL commercial computer is as a host operating station, monitoring, operation, management, data processing, report printing.

The host operating station and PLC master control station are connected by using the fiber Ethernet. The PLC main control station and the RIO station. are connected by coaxial cable fiber optic cable. The two controllers and two upper operating stations are connected by using the communication cable, data communication can be operated.

The system structure is shown as figure 1 .

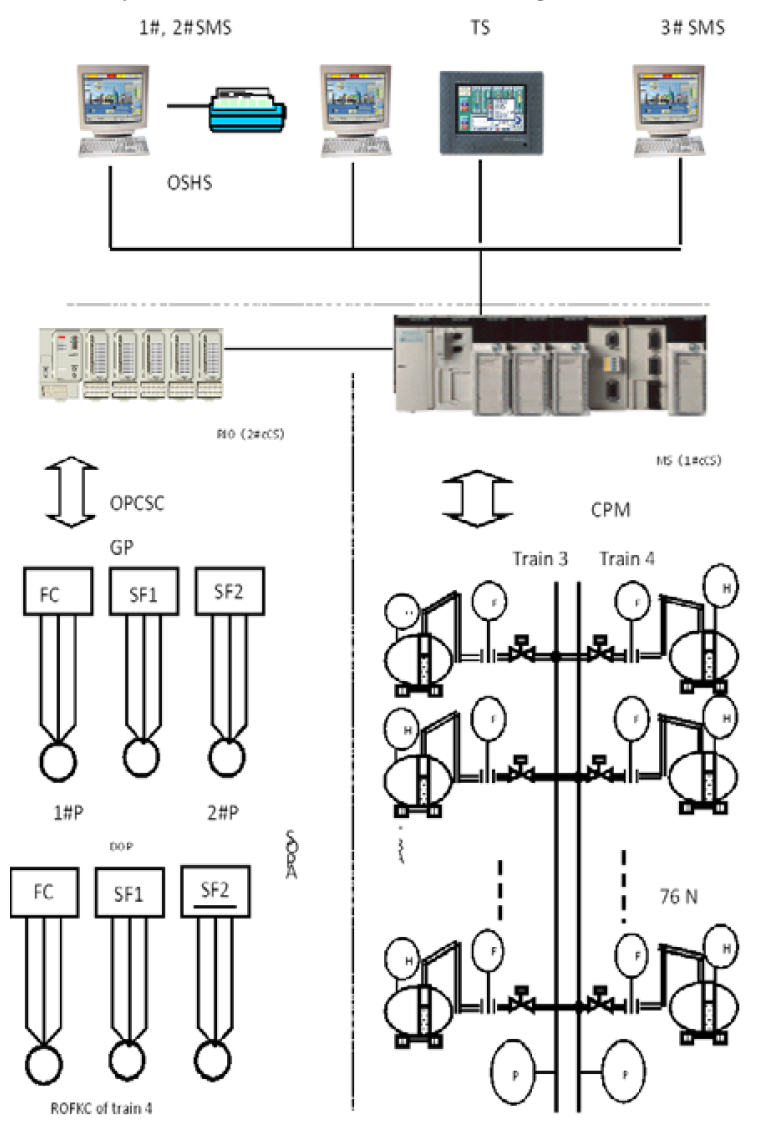

Fig.1. system structure figure

Here are follows in the figure 1.

SMS----Superior monitor station;P----Pump; N----

Number

TS----Touch screen; DOP----Diesel oil pump;

SF--Soft start

OSHS-----Operation station hot standby ;
SOPA-----Supply oil pump area

CS----Control station; ROFKC----Railway oil filling kind change

MS----Main station; TBA---------------Trestle bridge area OPCSC----Oil pump control and sign collect ;

FC----Frequency conversion

GP-----Gasoline pump;

CPM--------------Crane

position monitor

\subsection{The Function of the System}

\subsubsection{PLC control system}

According to the characteristics of process operation and equipment layout and process monitoring and management requirements of the run, is divided into two levels: level of operations management, production control level.

i) The operating management level: The comprehensive monitoring by the operator station all the information of the production control level, operating display, record, data processing, report output parameter modification operations and certain privileges. The standard TCP/IP protocol is used to communicate between the system controller and operator station, production and centralized management. The operations management level concludes the control room located in the office building \# 1, \# 2 upper monitoring stations and tank farm control room \# host monitoring station.

ii) The production control level: The control unit connected to the detection and control equipment to the production process real-time control, and is connected via Industrial Ethernet with the operating management level, to accept the operation of management information and transfer real-time data. Production control level controllers located trestle positive pressure explosionproof cabinet \# 1 and \# 2 located in the oil transmission oil pump operation control cabinet controllers.

\subsubsection{The main control station, RIO control station,}

\section{the upper monitor station}

The main control station is located in the stack the station end positive pressure explosion-proof cabinet, all the signals of the loading system were cited to stack station end of the positive pressure explosion-proof cabinet PLC the main control station, system communication is connected with the control room PC monitor in the control room to control and manage. The RIO controllers (\# 2 controllers) is located the control room of the tank area, 1 \#, 2 \# host monitoring station is located in the center control room of the office building. They are mutual redundancy.

The software of the upper station of the operator is InTouch8.0 that is run based on the Windows 2000 operating system. To ensure operation of the system is reliable, the man-machine interface the operator station that runs in real-time multitasking operating system, 
operating through a dedicated keyboard and mouse. The 3 \# host monitoring station is located in the tank area, the host computer and the upper software is similar with \# 1 , \# 2 upper control station.

\subsection{Automatic sorting of the pump}

The pump automatic sorting principle is as follows:

In every process, when the system setting up failure or the system detection failure, judgment to contactor failure, the pump the entrances valve failure, the drive does not work with failure, soft start does not work and failure, manifold pressure and pump current are abnormal; the faulty device can automatically be skipped. The other equipment can automatically be started to ensure the normal oil supply. When the last crane bit train tank will be filled (no other ready Crane-bit), the system will automatically stop the pump in order to prevent water hammer and pipe pressure out.

\subsection{The upper station operation}

The DELL commercial computer is as a host operating station, the automatic control software is equipped. The software is built by using the Intouch configuration software providing the software development environment. The configuration software can be configured for a variety of computer and software resources, computer or software in accordance with preset to automatically perform specific tasks to meet the requirements of users of different applications.

The data of the tank area, the light oil pumping station and train loading station are collected and proceed by using the system. The tank area real-time report printing function, history queries and print functions, level sound and light alarm, combustible gas concentration sound light alarm, liquid level and temperature of the tank area as well as oil and gas concentration history as well as the historical trend of the display, and maintenance functions are shown. The functions of the tank area and the light oil pumping station are monitored and managed.

Before operation the system, firstly, we have to enter the host operating system login screen. The system administrator for each user in the user configuration set different permissions, landing permissions are different, different functions and tasks can be completed. When a user completes his work or shift must exit the landing, to distinguish between landing work responsibilities. When a user logs on, the user enters the tank farm monitoring screen monitor. In this screen the name setting, density input, stack station monitoring, alarm function, report printing, historical trends, oil pump maintenance can be completed.

\section{Conclusions}

i) The system of the light oil railway loading is improved. The light oil loading in the train oil loading station is automatically.

ii) The oil pump control function is increased. The automatic filling, automatic oil pump control and tank area monitoring are combined. The whole process automation of the quantitative irrigation oil control and oil pump control are realized.

iii) It is obtained the significant effect in the safe production, energy efficient, reduce environmental pollution, improving economic efficiency aspects.

\section{References}

1. Shi Jianqiang. DDE interface between InTouch, Visual Basic and Matlab[J]. Journa of Nanjing Engineering Institute Natural\&ience Edition, 2003,1(1):29-35.

2. Hu Jinhui,Hu Dabin.Realization of control software based on DDE technology[J].Microcomputer Information, 2004, 20(1I):70-71.

3. Yang Yingjie,Deng Huiyong,Li Xia.Simulation of screening process based on Matlab/ simulink[J]. Jourhal of China University of Mining and Technology, 2006,16(3):330-332.

4. Jang B C,Choi G.Co-simulation and simulation integration for a full vehicle dynamic system[J]. Mathematical and Computer Modeling of Dynamica/ Systems, 2007,13(3):237-250.

5. Petropoulakis L,Stephen B.J-Sire:a GUI platform for real-time sharing of Matlab designs and simulation on the internet[J].International Journal of Continuing Engineering Education and Life Long Learning,2003,13(5-6):530-545.

6. MeArthar S D J,Davidson E M,Dudgeon G J W,et a1.Toward a model integration methodology for advanced application in power engineering[J].IEEE Transactions on Power System, 2003,18(3):5-6.

7. Xiao Min,Hui Lei.Direct communication between Matlab and Intouch. Journal of Jiangsu University, 2009, 0(1):60-65.

8. An Lianxiang, Cai Zhaojun, Zhang Shaoru,et,al. Design and application of Intouch in cold tandem mill control system.Computer Engineering, 2006, 32(22): 225-226.

9. QIANG Lixia.Model and algorithm of optimized organization scheme for through trains from loading points based on endpoint-for-weight[J].Journal of the China Railway Society,2009,31(6):91-96.

10. TANG Baogang.Study on the organization of wagon flow in heavy haul loading area[D].Beijing:Beijing Jiaotong University,2009.

11. CAO Xueming.WANG Xifu,LIN Boliang. Collaborative optimization model of the loaded \& empty car flow routing and the empty car distribution of multiple car types[J]. China Railway Science, 2009, 0(6):114-1 18.

12. Zhao Peng,Zhang Jinchuan,Tang Baogang.Study on the optimization model of car flow organization in the loading area of heavy haul railway based on the combined trains.China Railway Science, 2010, 31(6): 113-120.

13. Cai GuoQiang,Jia DongYue,Li Xiaofei.A incremental PID barrier control system used in railway crossing.International Journal of Advancements in Computing Technology, 2011, 3(4): $14 \sim 20$. 